\title{
Carta de Interpretação e Integração Geofísica-Geológica do Projeto Províncias Metalogenéticas do Brasil: Bloco Sudeste de Rondônia
}

\author{
Elias Martins G. Prado, Serviço Geológico do Brasil - CPRM; Guilherme Ferreira da Silva, Serviço Geológico do Brasil - \\ CPRM; Carlos Eduardo S. de Oliveira, Serviço Geológico do Brasil - CPRM.
}

\begin{abstract}
Copyright 2017, SBGf - Sociedade Brasileira de Geofísica
This paper was prepared for presentation during the $15^{\text {th }}$ International Congress of the Brazilian Geophysical Society held in Rio de Janeiro, Brazil, 31 July to 3 August, 2017.

Contents of this paper were reviewed by the Technical Committee of the $15^{\text {th }}$ International Congress of the Brazilian Geophysical Society and do not necessarily represent any position of the SBGf, its officers or members. Electronic reproduction or storage of any part of this paper for commercial purposes without the written consent of the Brazilian Geophysical Society is prohibited.
\end{abstract}

\section{Resumo:}

A carta geofísica-geológica consiste na representação gráfica de informações geofísicas de naturezas diversas confrontadas com o conhecimento geológico da área. $\mathrm{O}$ método utilizado consiste na delimitação e classificação de polígonos de mesma assinatura radiométrica, cujas cores variam de acordo com o teor de radioelementos; delimitação de zonas de alto magnético e extração de lineamentos estruturais de natureza magnética. Todas estas informações são representadas no mapa em conjunto com informações planimétricas.

\section{Introdução:}

A área de estudo compreende a porção sudeste do Estado de Rondônia e parte do extremo noroeste do Estado do Mato Grosso (Figura 1). O acesso à área pode ser feito por via rodoviária, pelas vias BR-364 e RO-339 que dá acesso aos municípios de Colorado do Oeste, Cerejeiras e Pimenteiras.

A área está inserida no contexto geotectônico do Cráton Amazônico, em sua porção sudoeste, dentro da Províncias Rondônia-Juruena. O substrato rochoso é constituído por uma sequência metassedimentar (Complexo Colorado), associadas a rochas máficas e ultramáficas (Complexo Trincheira), além de granitóides do tipo A. Estes litotipos foram fortemente deformados durante evento tectônico de idade $1.3 \mathrm{Ga}$., o qual imprimiu uma estruturação transpressiva desenvolvida sob condições metamórficas de fácies anfibolito superior.

\section{Metodologia/ Problema Investigado:}

O projeto aerogeofísicos Sudeste de Rondônia, utilizado na Integração e Interpretação Geofísica-Geológica, foi adquiridos ao longo de linhas de voo norte-sul, espaçadas em $500 \mathrm{~m}$ e a uma altura de voo de $100 \mathrm{~m}$, fornecendo, assim, os dados de magnetometria e gamaespectrometria (CPRM, 2006).

Os mapas magnéticos foram gerados a partir do Campo Magnético Anômalo que resulta da diferença entre o Campo Magnético Total (CMT) e o Campo Geomagnético de Referência (International Geomagnetic Reference Field). Os produtos gerados a partir do Campo Magnético Anômalo foram as Derivadas Vertical e Horizontal, Amplitude do Gradiente Horizontal Total, Amplitude do
Sinal Analítico, Inclinação do Sinal Analítico, entre outros. Os mesmos foram utilizados na interpretação dos lineamentos magnéticos de primeira e segunda ordens, assinatura de diques e delimitação de domínios com susceptibilidade magnética elevada.

O mapa de domínios gamaespectrométricos foi confeccionado a partir da composição colorida RGB dos canais de potássio $[\mathrm{K}]$, tório [eTh ] e urânio [eU ]. O produto foi classificado segundo a intensidade do sinal de cada radioelemento, gerando faixas de valores baixos, médios e altos associados a cada canal. Sendo assim, a combinação destas três intensidades nos três canais produziram 27 domínios gamaespectrométricos distintos e, consequentemente, o mapa ternário de falsa cor RGB apresenta um espectro de 27 cores. Os domínios gamaespectrométricos interpretados foram correlacionados com os litotipos aflorantes na região.

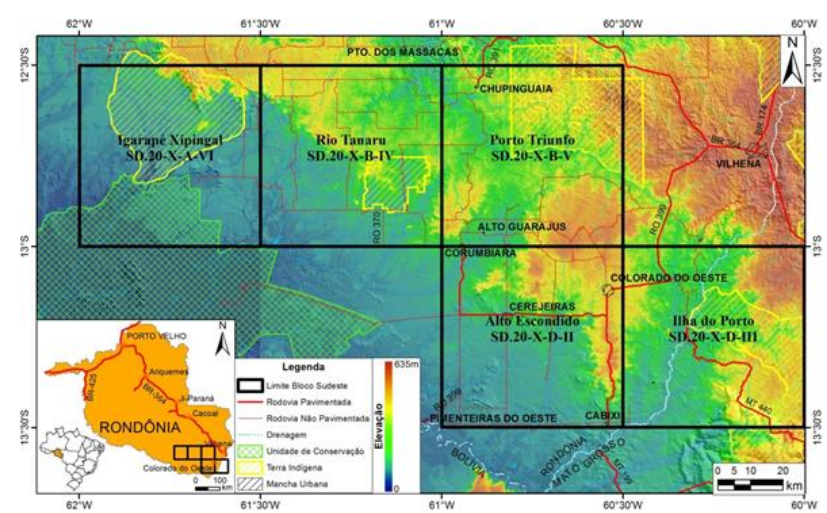

Figura 1: Localização da área de trabalho no sudeste do estado de Rondônia e articulação das folhas 1:100.000 recobertas na pesquisa.

O Mapa de Densidade de Estruturas Magnéticas representa as descontinuidades magnéticas em profundidades distintas relacionadas à estruturação tectônica da região (Figura 2).

As anomalias pontuais do mapa de concentração de radioelementos (Figura 3 ) foram calculadas a partir da análise histogrâmica dos valores de potássio, tório equivalente e urânio equivalente. Foram considerados valores anômalos aqueles superiores ao valor da mediana acrescido de três vezes o desvio padrão de cada radioelemento.

\section{Resultados:}

Quatro domínios com predominância da classe ASA alta foram descriminados na área de pesquisa. O domínio A1 é caracterizado por uma anomalia de formato irregular localizado na porção sudeste da área. A componente principal, de alta amplitude magnética, possui formato 
circular com aproximadamente $7 \mathrm{~km}$ de diâmetro, situada ao norte deste domínio.

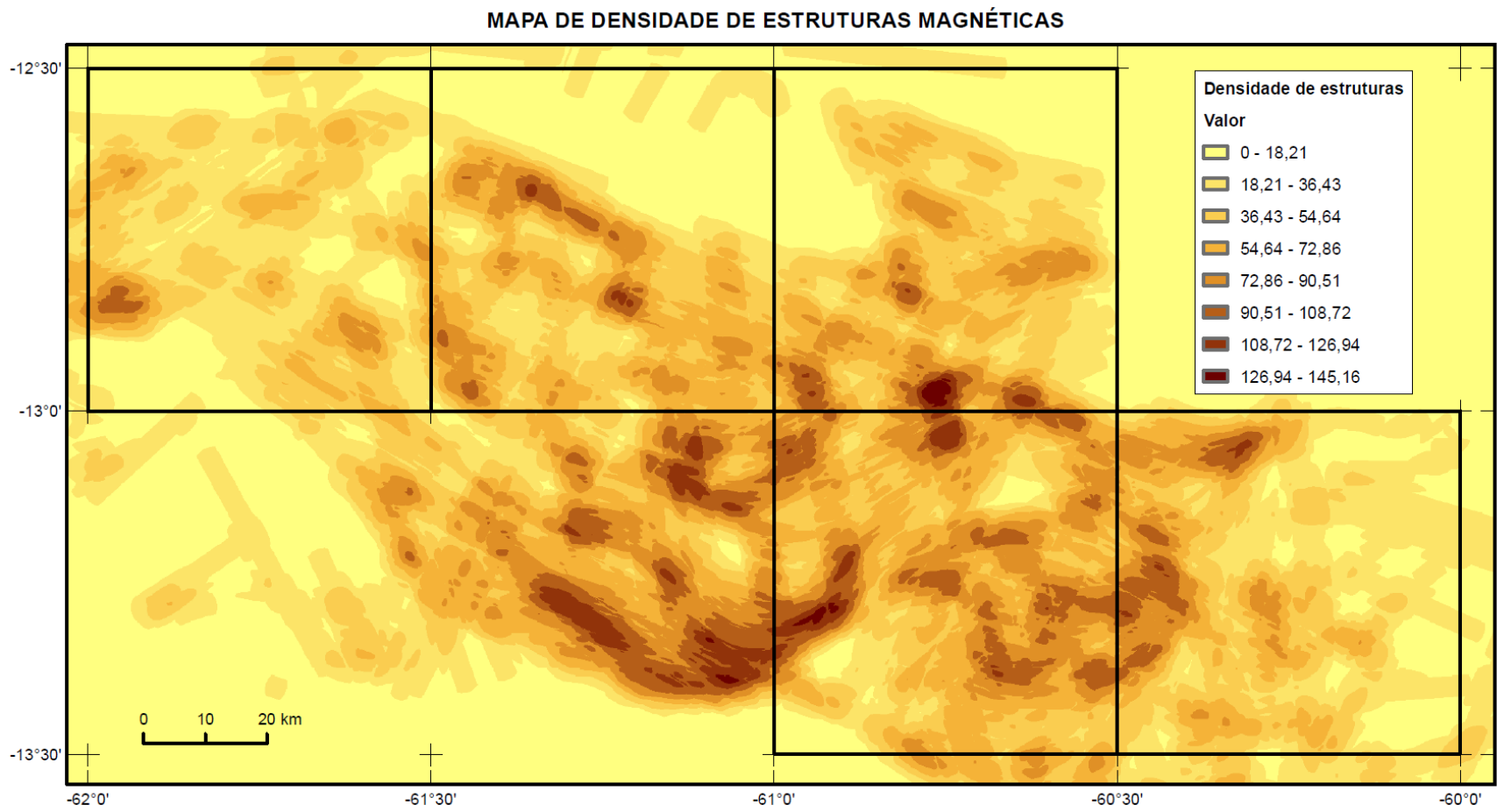

Figura 2: Mapa de densidade de lineamentos magnéticos interpretados. As zonas com maior ocorrência de estruturas estão coloridas em tom de marrom escuro.

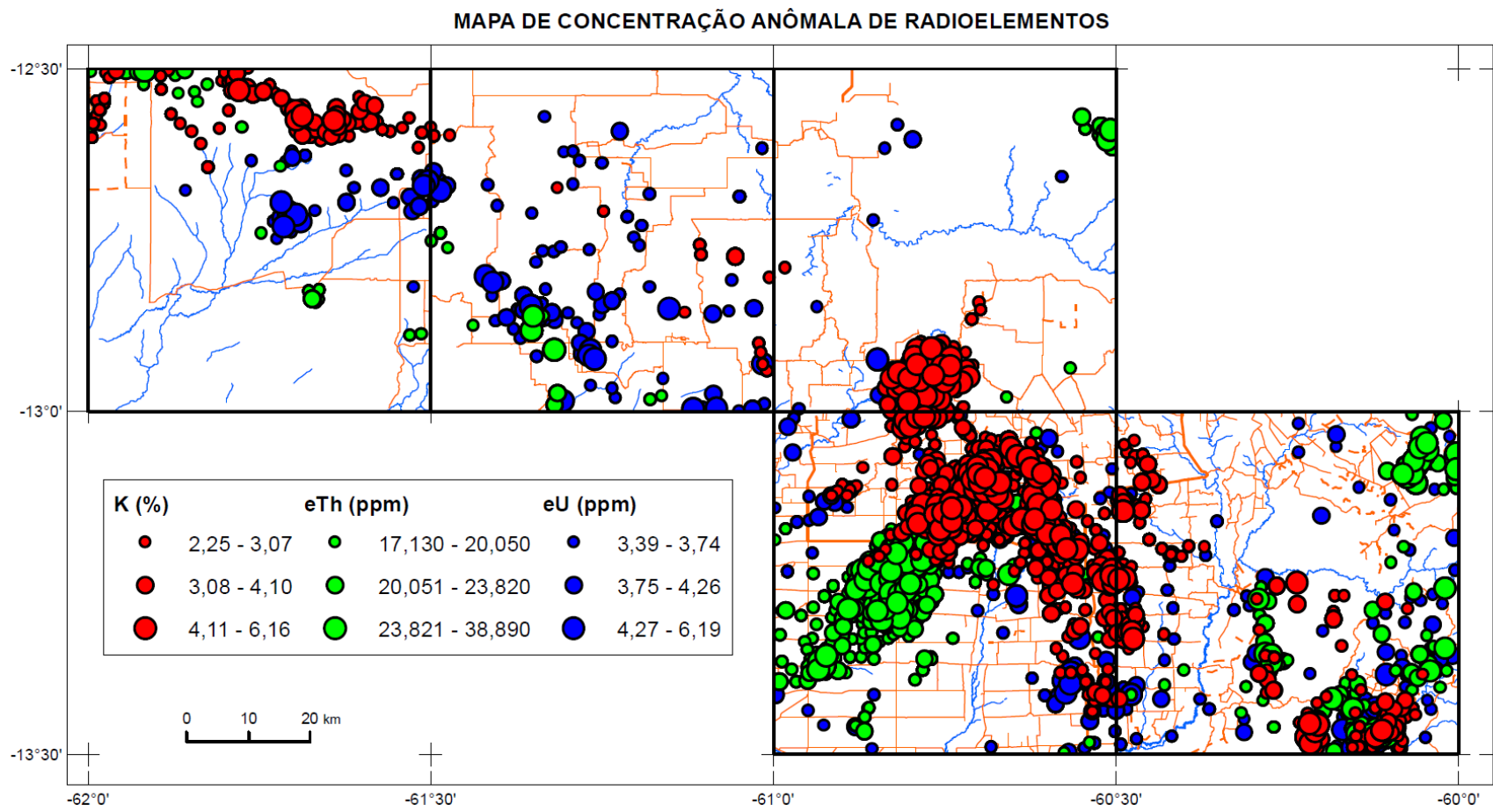

Figura 3: Mapa de concentração anômala de radioelementos. Os círculos estão representados segundo cada elemento (vermelho - potássio; verde - tório e azul - urânio) e segundo os valores locais (maior raio significa maior concentração). 
A porção norte desta anomalia é fracamente magnética sendo limitada por um forte lineamento magnético de direção WNW/ESE. A ENE desta anomalia se encontram anomalia menores alongadas em duas direções principais, NE/SW e NW/SE, que tangenciam a anomalia circular principal. Abaixo da anomalia principal, uma assinatura magnética elipsoidal alongada segundo NW/SE com o eixo maior de $6 \mathrm{~km}$ pode ser vista. Anomalias menores ao meio de uma textura magnética rugosa recobrem o restante do domínio. O domínio A2 apresenta anomalias alongadas segundo a direção NW/SE que se estendem por aproximadamente $25 \mathrm{~km}$, e anomalias menores alongadas segundo NNW/SSE e NNE/SSW. O domínio A3 é representado por assinaturas magnéticas que se encontram principalmente alongadas segundo as direções EW, NE/SW e NW/SE, e uma anomalia circular com $4 \mathrm{~km}$ de diâmetro localizada na porção central da área. O domínio A4 apresenta uma anomalia alongada segunda a direção NE/SW com $15 \mathrm{~km}$ de extensão no seu eixo maior, com predominância de valores ASA maiores que $0,225 \mathrm{nT} / \mathrm{m}$. Esta assinatura representa geologicamente um corpo da Suite MáficaUltramáfica Serra Céu Azul, definido como olivina-gabro e metagabros com potencial para $\mathrm{Cr}$, Ni e $\mathrm{Cu}$ (Romanini, 1997).

O domínio MA1 compreende as assinaturas com predominância das classes média alta à alta. Este domínio é marcado por anomalias magnéticas pequenas ao meio de uma textura rugosa, com algumas anomalias alongadas que sugerem uma inflexão das estruturas magnéticas N50W para N35E, no centro do domínio, sugerindo uma grande descontinuidade crustal marcada por falhas, que apresentam componente transcorrente sinistral predominante. No sul deste domínio ocorrem algumas anomalias alongadas segundo a direção N50W que se estendem por $40 \mathrm{~km}$, associadas a anomalias menores, com extensão de $7 \mathrm{~km}$, alinhadas EW. A correlação com unidades geológicas é dificultada pela cobertura de sedimentos cenozoicos da Bacia do Guaporé. A parte aflorante é correlacionada ao Complexo Máfico-Ultramáfico Trincheira, onde exibe a continuidade desta unidade abaixo dos sedimentos da bacia. $\mathrm{O}$ domínio MA2 tem aproximadamente $25 \mathrm{~km}$ de extensão em seu eixo maior, alinhado segundo NNE, e apresenta uma textura magnética rugosa com as classes magnéticas mais altas se concentrando a norte do domínio e é correlata a granulitos máficos da unidade Trincheira. O domínio MA3 apresenta textura característica, com predomínio de anomalias de pequeno comprimento de onda, e intensidade magnética variando de média a média alta, com alguns picos anômalos acima de $0,225 \mathrm{nT} / \mathrm{m}$. Este domínio se estende por $100 \mathrm{~km}$ em seu eixo maior. A alta frequência das anomalias deste domínio e o seu desaparecimento na continuação ascendente de $10.000 \mathrm{~m}$ sugerem que as fontes magnéticas do domínio se encontram próximas a superfície.

Os domínios M1 representam anomalias de média intensidade magnética formando a periferia de domínios de maior amplitude. Estes domínios apresentam feições curvadas impostas pela deformação seguindo o trend local. O domínio M2 tem formato circular com aproximadamente $10 \mathrm{~km}$ de diâmetro, predominando valores médios de intensidade magnética.

Os domínios $\mathrm{MB}$ e $\mathrm{B}$ são assinalados como baixos magnéticos, ocorrendo por toda a área de pesquisa, em formatos de grande dimensão, representa arcabouço geológico com relevo magnético menos rugoso. Na porção norte, o baixo magnético é associado à Bacia dos Parecis. Bettencourt et al. (2010), descriminam os Terrenos Paraguá e Jauru a sul e leste, respectivamente, da área de estudo. Os baixos valores de susceptibilidade magnética dos domínios B1 e B2 estão associados a estes terrenos.

Os lineamentos magnéticos representam descontinuidades magnéticas em profundidades distintas relacionadas à estruturação tectônica da região. Os lineamentos magnéticos de caráter rasos, extraídos do ISA e AGHT, foram diferenciados temporalmente através das relações de corte, o que possibilitou a identificação de três eventos de deformação na região (Erro! Fonte de referência não encontrada.). Os lineamentos relacionados ao evento D1 são os que predominam na área de estudo. Entretanto, grande parte destes lineamentos magnéticos se encontram encobertos pelos sedimentos cenozoicos da Bacia do Guaporé, dificultando o entendimento da estruturação deste evento através de dados estruturais de campo.

A estruturação D1 apresenta textura sinuosa com direção preferencial para N50W. No centro da área de estudo estes lineamentos flexionam para NE, na forma de um "S", retornando para N50W a leste. Esta zona é marcada no mapa ASA residual por um aumento na amplitude magnética e na densidade de lineamentos magnéticos. $A$ morfologia destes lineamentos sugere uma movimentação sinistral, onde 0 seguimento crustal localizado a leste desta zona se movimentou para NE em relação ao seguimento crustal a oeste da zona. A leste desta zona é possível observar uma faixa de aproximadamente $36 \mathrm{~km}$ de largura por $32 \mathrm{~km}$ de comprimento com alta amplitude magnética e grande densidade de lineamentos magnéticos na direção N50W. Esta faixa é limitada a leste por um forte gradiente magnético, caracterizado por estruturas anastomosadas na direção NNW que truncam os lineamentos da estruturação D1, marcando a estruturação D2. Nos trabalhos de Rizzotto (2010) e Rizzotto et al. (2013), a estruturação da Faixa Alto Guaporé é caracterizada por grandes zonas de cisalhamento dúcteis e crenulação sintectônicos que paralelizam as estruturas prévias. Por analogia, provavelmente o evento D1 está relacionado a esta estruturação, que ocorreu durante o mesoproterozoico, entre 1.459-1.329 Ma, baseado em dados geocronológicos de Rizzotto et al. (2013).

O padrão de deformação D2 é relacionado aos lineamentos anastomosados com trend NNW verificado na porção sudeste da área de pesquisa. Estes lineamentos truncam as estruturas lineares do evento D1, e se encontram acima de um forte gradiente magnético, o qual limita um segmento crustal magnético a oeste de um seguimento crustal fracamente magnético a leste. Esta 
descontinuidade segue o mesmo trend estrutural do lineamento Rio Vermelho (Suíte intrusiva Pindaituba) no Terreno Jauru, provavelmente associada à orogenia Sunsás.

A estruturação D3 é caracterizada por grandes lineamentos magnéticos retilíneos nas direções N35E, $\mathrm{EW}, \mathrm{N} 50 \mathrm{~W}$ e N20W que cortam toda a extensão da área de pesquisa. Certamente, estes lineamentos estão relacionados a estruturas rúpteis, que aproveitam a anisotropia crustal gerada nos eventos D1 e D2. A maior densidade destes lineamentos magnéticos concentramse na porção norte da área de pesquisa, região correspondente a borda sul do Grabén do Colorado, pertencente a Bacia dos Parecis. Por correlação, estas estruturas possivelmente foram ativadas durante a abertura da Bacia dos Parecis no Mesozoico.

O domínio 1 representa unidades radiométricas com alta concentração nos três radioelementos, à exemplo das zonas externas dos plútons Cerejeiras e Alto Escondido, assim como xistos e paragnaisses do Complexo Colorado mesclados à injeções graníticas concordantes à foliação metamórfica. O domínio 2 representa unidades enriquecidas em $\mathrm{K}$ e eTh, porém depletadas em eU, estaresposta é característica do núcleo dos plútons Cerejeiras e Alto Escondido. O domínio 3 representa unidades radiométricas enriquecidas em $\mathrm{K}$ e eTh e moderadamente depletadas em eU. Representa unidades da bacia a noroeste da área de trabalho, assim como drenagens largas carreando grande quantidade de sedimentos (vale do Rio Escondido). O domínio 4 representa unidades radiométricas enriquecidas em $\mathrm{K}$ e eU e depletadas em eTh, correspondendo aos tons de magenta no mapa ternário RGB (Erro! Fonte de referência não encontrada.-A). $O$ domínio 5 representa unidades enriquecidas em $\mathrm{K}$ e depletadas nos demais radioelementos. O domínio 6 representa unidades enriquecidas em $\mathrm{K}$ e eU, com concentrações intermediárias de eTh. Os domínios 7 e 8 representam unidades enriquecidas em eTh, porém variando em relação aos demais elementos. Estes domínios juntos cobrem a maior parte da área de trabalho e podem ser atribuídos às coberturas fanerozoicas da bacia do Guaporé (porção sudoeste da área de trabalho), assim como às rochas da formação Utiariti. O domínio 9 representa unidades enriquecidas em eU e depletadas nos demais elementos. Ocorre em regiões na borda da bacia do Guaporé e em algumas rochas do Complexo Trincheiras. O domínio 10 representa unidades radiométricas depletadas nos três radioelementos e recobre rochas máficas e ultra-máficas do Complexo Trincheiras, rochas sedimentares da bacia do Parecis e terrenos alagados na planície do Guaporé. O domínio 11 representa rochas depletadas em $\mathrm{K}$ e com concentrações medianas de eTh e eU. Este domínio cobre rochas e coberturas do norte da área de trabalho e coincide com exposições de basaltos da formação Anari e com o solo decomposto de origem desta rocha. O domínio 12, último entre os individualizados, também apresenta reposta intermediária em eTh e eU, porém com uma a assinatura textural distinta do último domínio, motivo utilizado para individualizá-lo.
A partir da análise conjunta dos domínios e das formas de relevo, as unidades radiométricas foram classificadas como correspondentes a resposta derivada de rochas do "cristalino" e rochas e sedimentos da "cobertura fanerozoica". Esta figura serve para verificar a correlação entre 0 alinhamento e as formas dos domínios gamaespectrométricos com os domínios e lineamentos magnéticos apresentados anteriormente nos tópicos 4.4.1 e 4.4.2, que apresenta a direção preferencial de estruturas da crosta rasa, por vezes encoberta por rochas fanerozoicas.

De modo geral, os domínios gamaespectrométricos correspondentes à porção de rochas do cristalino apresentam uma estruturação preferencial de acordo com tendências direcionais NW-SE e NNE-SSW. Tal tendência também está presente nos domínios e lineamentos magnéticos interpretados anteriormente.

\section{Discussão e Conclusões:}

Os dados aerogeofísicos mostram que o sudeste do Estado de Rondônia possui uma história tectônica complexa com distintos eventos de deformação superimpostos. As bacias sedimentares Fanerozoicas (Bacia do Parecis, Bacia do Guaporé) recobrem grande parte da região, dificultando o mapeamento de importantes feições geológicas do embasamento. Neste sentido, é determinante a integração dos dados aerogeofísicos e dos dados coletados em campo para o avanço no entendimento geológico da região.

A análise dos dados magnéticos permitiu a individualização de segmentos crustais com assinaturas magnéticas distintas, auxiliando o entendimento tectônico da região (Figura 4). A extração dos lineamentos magnéticos possibilitou a caracterização do arcabouço estrutural da região. As assinaturas de estruturas magnéticas de fonte profunda encontram-se em duas direções principais, N50W e N35E. Estes lineamentos provavelmente representam grandes descontinuidades crustais, relacionadas à aglutinação de terrenos com assinaturas magnéticas distintas, e estão associados aos limites entre a Faixa Alto Guaporé e os terrenos Paragua e Jauru. O mapa de pseudogravidade da área reforça a presença destas descontinuidades profundas. Os lineamentos magnéticos mais rasos, extraídos do ASA residual, foram diferenciados temporalmente através das relações de corte, o que possibilitou a identificação de três eventos de deformação na região. Os lineamentos mais antigos, relacionados ao evento D1, provavelmente, estão associados com a orogenia mesoproterozoica entre - Terreno Paraguá e o proto-cráton Amazônico, descrita por Loewy et al. (2004), Boger et al. (2005) e Rizzoto et al, (2012). Os lineamentos relacionados ao evento D2 são os de menor expressão na área de estudo e seguem o mesmo trend estrutural do lineamento Rio Vermelho (Suíte Intrusiva Pindaiatuba) no Terreno Jauru, noroeste do Mato Grosso, associado à orogenia Sunsás. A estruturação D3 é caracterizada por grandes lineamentos magnéticos retilíneos relacionados a estruturas rúpteis, que aproveitaram a anisotropia crustal gerada nos eventos D1 e D2. Estas estruturas possivelmente foram 
ativadas durante a abertura da Bacia dos Parecis no Mesozoico.

A integração dos dados radiométricos permitiu elaborar o mapa de domínios gamaespectométrico (Figura 5), este mapa tornou possível a individualização das bacias sedimentares Fanerozoicas e o detalhamento dos litotipos do embasamento Proterozoico, como a separação dos principais conjuntos de rochas que afloram na área de pesquisa. A partir desta análise é possível notar a influência de coberturas sedimentares da Bacia do Guaporé, na porção sudoeste da área de trabalho e de rochas da Bacia do Parecis, nas porções norte e nordeste. De tal modo, as rochas do embasamento estão condicionadas a uma estreita faixa de direção noroeste/sudeste, concordante parcialmente com a tendência direcional de estruturação das mesmas. Verificou-se posteriormente se estas assinaturas radiométricas possuíam correlação com as unidades geológicas mapeadas, ou com feições hidrográficas presentes na região. Portanto, a gamaespectrometria correspondeu à principal ferramenta aerogeofísica para descrever as feições superficiais, seja correspondente a rocha ou ao regolito.

\section{Agradecimentos:}

Esta pesquisa é decorrente do Projeto Províncias Metalogenéticas do Brasil: Bloco Sudeste de Rondônia, desenvolvido pelo Serviço Geológico do Brasil com recursos do Programa de Aceleração do Crescimento (PAC). Este trabalho também contou com a contribuição da equipe da Residência de Porto Velho (REPO), Rondônia, Diretoria de Geologia e Recursos Minerais (DGM), CPRM.

\section{Referências:}

BETTENCOURT, J. S. et al. The Rondonian-San Ignacio Province in the SW Amazonian Craton: an overview. Journal of South American Earth Sciences, v. 29, p. 28-46, 2010.

BOGER, S. D. et al. U-Pb age data from the Sunsas region of Eastern Bolivia, evidence for the allochthonous origin of the Paragua Block. Precambrian Research, v. 139, p. 121-146, 2005.

CPRM - SERVIÇO GEOLÓGICO DO BRASIL. Projeto aerogeofísico sudeste de Rondônia: relatório final de levantamento e processamento dos dados magnetométricos e gamaespectrométricos. Rio de Janeiro: Lasa Engenharia e Prospecções; Prospectors Aerolevantamentos e Sistemas, 2006. 27v

LOEWY, S.L., CONNELLY, J.N. AND DALZIEL, I.W., 2004. An orphaned basement block: the ArequipaAntofalla Basement of the central Andean margin of South America. Geol Soc Am Bull 116: 171-187.

RIZZOTTO, G. J. (Org.). Geologia e recursos minerais da folha Pimenteiras SD.20-X-D: texto explicativo do mapa geológico e de recursos minerais da folha Pimenteiras. Porto Velho: CPRM, 2010. 136 p.
RIZZOTTO, G. J. et al. The ectasian Guaporé suture in the sw amazon craton: geotectonic implications. In: CONGRESSO BRASILEIRO DE GEOLOGIA, 46.; CONGRESSO DE GEOLOGIA DOS PAISES DE LINGUA PORTUGUESA, 1., 2012, Santos. Anais... Santos: SBG, 2012.

RIZZOTTO, G. J. et al. The Mesoproterozoic Guaporé suture in the SW Amazonian Craton: geotectonic implications based on field geology, zircon geochronology and $\mathrm{Nd}-\mathrm{Sr}$ isotope geochemistry. Journal of South American Earth Sciences, v. 48, p. 271-295, 2013.

ROMANINI, S. J. Mapa geológico preliminar da Serra Céu Azul/RO: prospecção geoquímica e síntese geológico-metalogenética. Porto Alegre: CPRM, 1997. (Informe de Recursos Minerais. Série Metais do Grupo da Platina, 03). Programa Nacional de Prospecção de Metais do Grupo da Platina. 


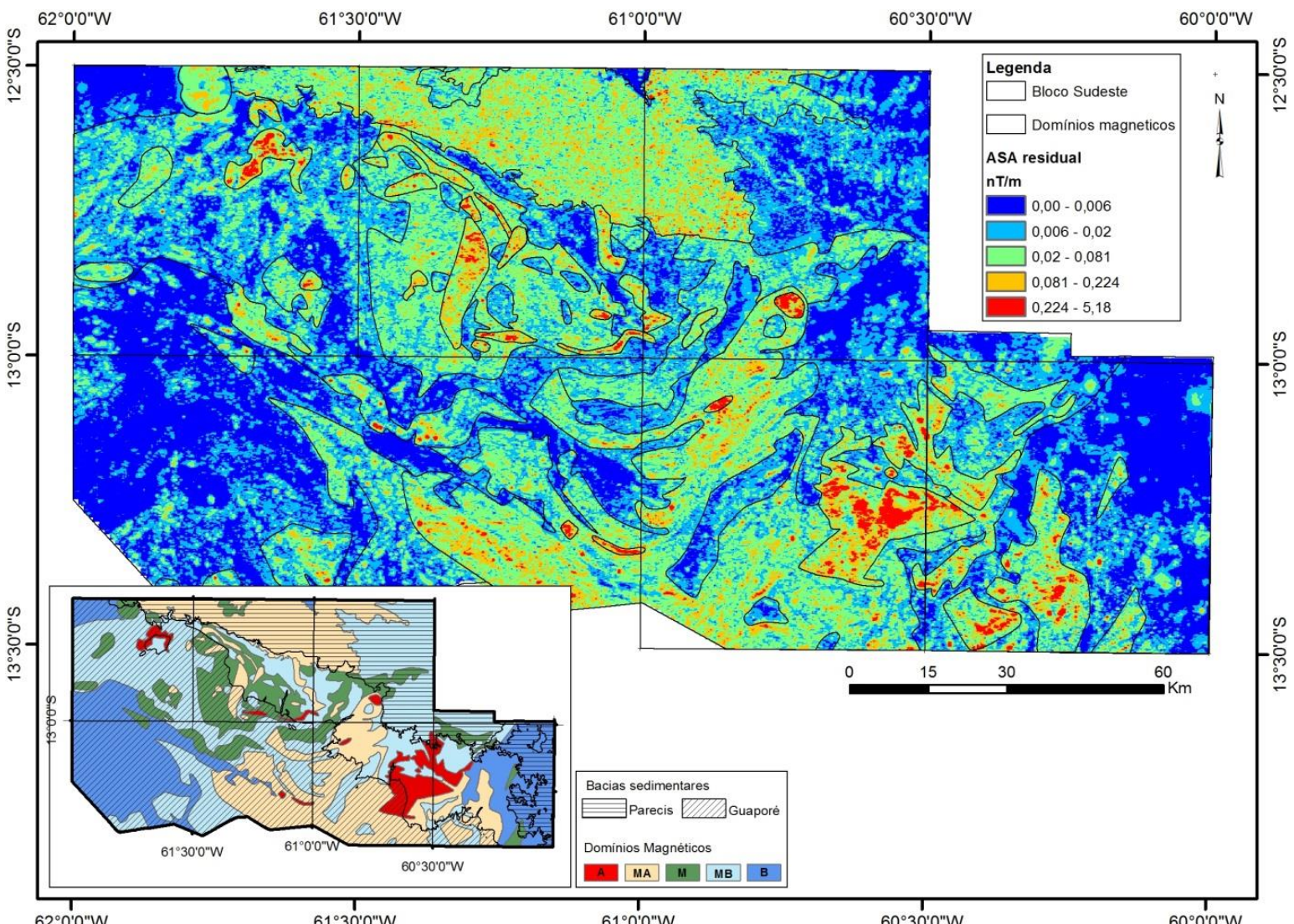

Figura 4: Mapa de domínios magnéticos e mapa da amplitude do sinal analítico reclassificado para cinco classes de intervalos com a demarcação dos domínios interpretados.

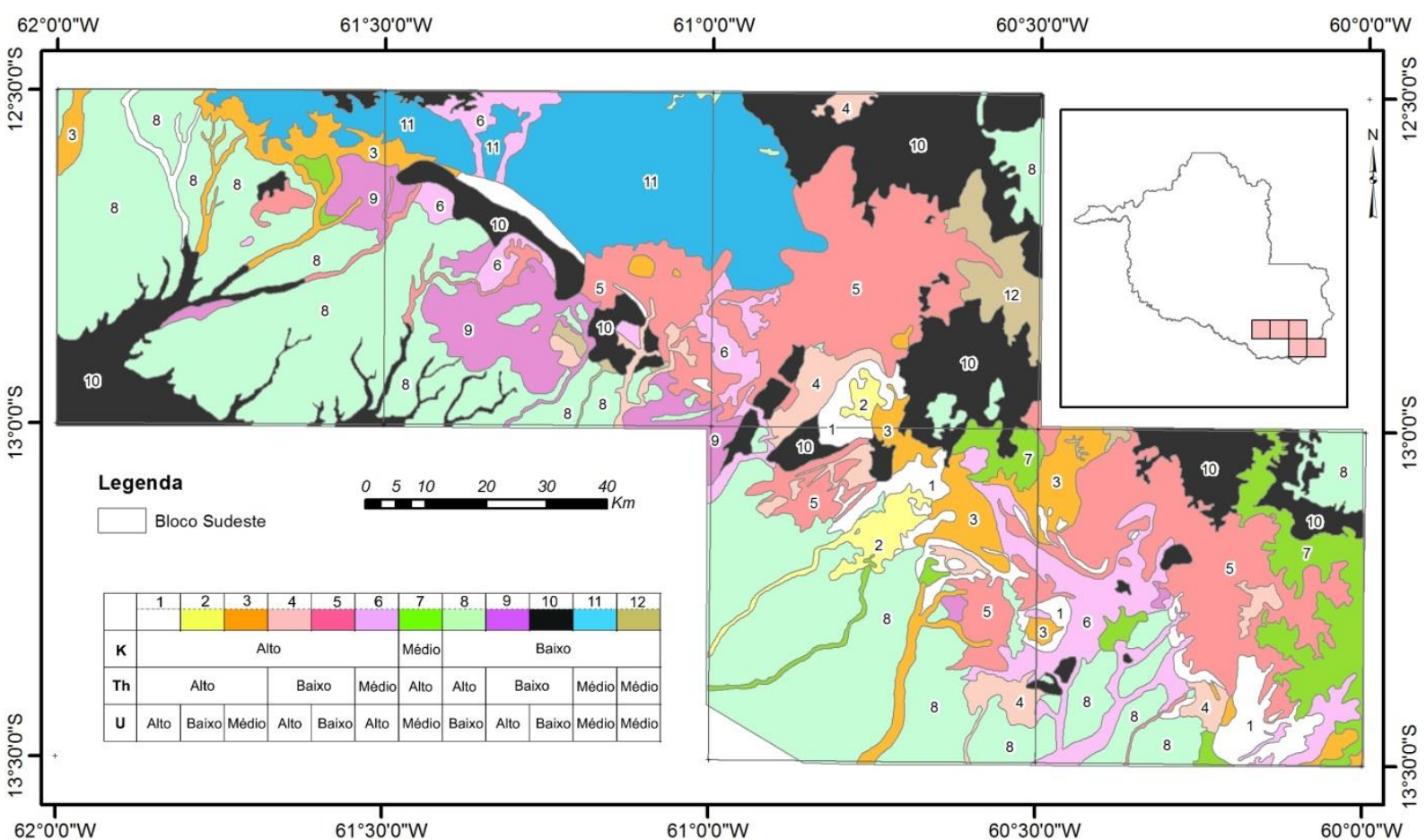

Figura 5: Mapa de domínios radiométricos e carta de interpretação de cores por concentração de radioelemento. 